\title{
Combinatorial treatment using targeted MEK and SRC inhibitors synergistically abrogates tumor cell growth and induces mesenchymal-epithelial transition in non-small-cell lung carcinoma
}

\author{
Kian Ngiap Chua ${ }^{1,{ }^{*}}$, Li Ren Kong ${ }^{1,{ }^{*}}$, Wen Jing Sim ${ }^{2,}{ }^{*}$, Hsien Chun $\mathbf{N g}^{2}$, \\ Weijie Richard Ong ${ }^{3}$, Jean Paul Thiery ${ }^{1,2,4}$, Hung Huynh ${ }^{3}$, Boon Cher Goh ${ }^{1,5,6}$ \\ ${ }^{1}$ Cancer Science Institute of Singapore, National University of Singapore, Singapore \\ ${ }^{2}$ Institute of Molecular and Cell Biology, A*STAR, Singapore \\ ${ }^{3}$ National Cancer Centre, Singapore \\ ${ }^{4}$ Department of Biochemistry, Yong Loo Lin School of Medicine, National University of Singapore, Singapore \\ ${ }^{5}$ Department of Hematology-Oncology, National University Hospital, Singapore \\ ${ }^{6}$ National University Cancer Institute, Singapore \\ * These authors have contributed equally to this work \\ Correspondence to: \\ Boon Cher Goh, e-mail: phcgbc@nus.edu.sg \\ Keywords: mesenchymal-epithelial transition inducer, MEK and SRC inhibitor combination treatment, PD0325901, saracatinib, \\ non-small-cell lung cancer \\ Received: April 21, 2015 \\ Accepted: August 07, 2015 \\ Published: August 17, 2015
}

\section{ABSTRACT}

Oncogenesis in non-small cell lung cancer (NSCLC) is regulated by a complex signal transduction network. Single-agent targeted therapy fails frequently due to treatment insensitivity and acquired resistance. In this study, we demonstrate that co-inhibition of the MAPK and SRC pathways using a PD0325901 and Saracatinib kinase inhibitor combination can abrogate tumor growth in NSCLC. PD0325901/ Saracatinib at 0.25:1 combination was screened against a panel of 28 NSCLC cell lines and $68 \%$ of cell lines were found to be sensitive $\left(\mathrm{IC}_{50}<2 \mu \mathrm{M}\right)$ to this combination. In Snail1 positive NSCLC lines, the drug combination complementarily enhanced mesenchymal-epithelial transition (MET), increasing both E-cadherin and Plakoglobin expression, and reducing Snail1, FAK and PXN expression. In addition, the drug combination abrogated cell migration and matrigel invasion. The co-inhibition of MAPK and SRC induced strong G1/G0 cell cycle arrest in the NSCLC lines, inhibited anchorage independent growth and delayed tumor growth in H460 and H358 mouse xenografts. These data provide rationale for further investigating the combination of MAPK and SRC pathway inhibitors in advanced stage NSCLC.

\section{INTRODUCTION}

Lung cancer is one of the leading causes of cancer mortality in many countries [1-3]. Approximately $85 \%$ of all lung cancers are non-small cell lung cancers (NSCLC), which can be further subclassified into squamous cell carcinoma, large cell carcinoma and adenocarcinoma. Despite significant therapeutic advances made in recent decades, the 5-year survival rate for lung cancer remains at less than $17 \%[2,3]$. In general, the effectiveness of chemotherapy, radiotherapy and surgery have been unsatisfactory, especially in the treatment of advanced NSCLC [4]. Thus, new treatment strategies that target the molecular and cellular events underlying the development of this fatal disease are urgently needed.

The introduction of targeted therapeutics for cancer treatment in recent years has significantly changed the practice of medical oncology and many targeted 
therapeutics are being validated in various stages of clinical development. Some of these targeted compounds, such as Gefitinib and Erlotinib, have been approved for first-line treatment to treat advanced NSCLC harboring sensitive epidermal growth factor receptor (EGFR) mutations $[5,6]$. Unfortunately, these targeted therapies will eventually limit the effectiveness of traditional chemotherapies in the metastatic disease due to the relatively rapid acquisition of drug resistance developed by the tumor cells [7]. In NSCLC, studies have shown that secondary mutations (T790M) in the EGFR kinase domain can promote resistance to EGFR inhibitor treatment [8]. Furthermore, EGFR can crosstalk with other growth factor receptors, such as insulin-like growth factor-I receptor (IGF-IR), and reduces the effectiveness of Erlotinib treatment through the activation of the AKT signaling pathway [9].

Studies have therefore begun to investigate on the application of targeted drug combinations to abrogate signaling pathways cross-talk and restore treatment sensitivity $[10,11]$. For example, Sos et al demonstrated in NSCLC cell lines that combined blockade of phosphatidylinositol-4,5-bisphosphate 3-kinase (PI3K) and mitogen-activated protein kinase (MAPK) pathways could overcome the reciprocal pathway activation induced by inhibitor-mediated feedback loops and resulted in significant increase in apoptosis and tumor shrinkage [10]. Likewise, Legrier et al also showed that combined inhibition of MAPK and mammalian target of rapamycin (mTOR) synergistically suppressed proliferation in NSCLC cell lines and induced regression of xenograft tumors [11]. Due to the shear diversity of this topic, it is foreseeable that other targeted drug combinations may be proven to be effective and may become viable lung cancer treatments in the future.

Studies have also focused on non-genetic mechanisms such as Epithelial Mesenchymal Transition (EMT) as a cause of tumor cell dissemination and drug resistance in cancer therapy [4, 12-15]. EMT is a crucial mechanism for carcinoma progression, as it provides routes for in situ carcinoma cells to dissociate and become motile, leading to localized invasion and metastatic spread. Indeed, bone, brain, lymph nodes, liver and adrenal glands metastases are a very common secondary localization of disease in lung cancer patients, with $30-40 \%$ of patients developing brain and bone metastases in the course of their disease [16, 17]. Targeting EMT therefore represents an important therapeutic strategy for the treatment of advanced NSCLC exhibiting highly invasive and metastatic phenotype $[14,15]$. We have hypothesized that some targeted therapeutics, whilst initially optimized as anti-proliferative agents, may also inhibit EMT initiation and sustenance, since they are both regulated by similar signaling pathways that these compounds were designed to inhibit [15]. However, in-depth investigations to characterize existing targeted drugs on EMT modulating properties are still limited to date. We had recently discovered through a novel cell-based, high-content EMT screening assay, that two targeted compounds, PD0325901 and Saracatinib, selective inhibitors of MEK and SRC kinases respectively, were also potent EMT modulators that could interfere with EGF, HGF, and IGF-1 induced EMT signaling in a NBT-II EMT reporter cell line [14].

In this study, we investigate whether PD0325901 and Saracatinib co-treatment can synergistically suppress cell proliferation and tumorigenicity in NSCLC lines. We also evaluate the impact of PD0325901 and Saracatinib in modulating the EMT process via induction of Mesenchymal-Epithelial Transition (MET) in NSCLC lines. Specifically, we also determine whether PD0325901 and Saracatinib in combination can induce strong antitumor and MET response across multiple NSCLC lines.

\section{RESULTS}

\section{Cell proliferation inhibition effects of PD0325901 or Saracatinib single drug treatments on lung cancer cell lines}

We investigated on the proliferation inhibition effects of PD0325901 and Saracatinib as single drug therapies on a collection of 28 lung cancer cell lines. We found that only 8 out of 28 cell lines (29\%) were sensitive to PD0325901 treatment (cell proliferation $\mathrm{IC}_{50}<2 \mu \mathrm{M}$ ), while 15 cell lines (54\%) were considered resistant to this compound (cell proliferation $\left.\mathrm{IC}_{50}>10 \mu \mathrm{M}\right)$ (Fig. 1A). In general, the growth inhibition response to PD0325901 varied widely, with cell lines responding highly sensitively (H1437 and H1666, $\left.\mathrm{IC}_{50}<50 \mathrm{nM}\right)$, to cell lines that were highly resistant (H1650 and $\left.\mathrm{H} 2170, \mathrm{IC}_{50}>100 \mu \mathrm{M}\right)$. For Saracatinib single drug treatment, 9 cells lines $(32 \%)$ were observed to be sensitive, while 11 cell lines (39\%) were found to be resistant (Fig. 1B). The growth inhibition response to Saracatinib was observed to be less varied, with the $\mathrm{IC}_{50}$ ranging from $150 \mathrm{nM}$ (PC-9) to $33 \mu \mathrm{M}$ (H460). No correlation between the cell lines' sensitivity to these two compounds was observed.

\section{PD0325901 synergized with Saracatinib co-treatment to reduce cell proliferation in lung cancer cell lines}

We next investigated on the proliferation inhibition effects of PD0325901 (PD) and Saracatinib (AZ) co-treatment on the lung cancer cell lines. We generated the drug response profiles of three different PD0325901 / Saracatinib co-treatments at fixed PD:AZ combination ratios of $4: 1,1: 1$ and $0.25: 1$ for each cell line (Fig. 1C and Supplemental Fig. 1). We then performed synergism analysis by comparing the growth inhibition effects of the single drugs to the drug combinations. The drug combination indices for between the 50\%-80\% growth inhibition range were then calculated using the Loewe Additivity model that had been used extensively 

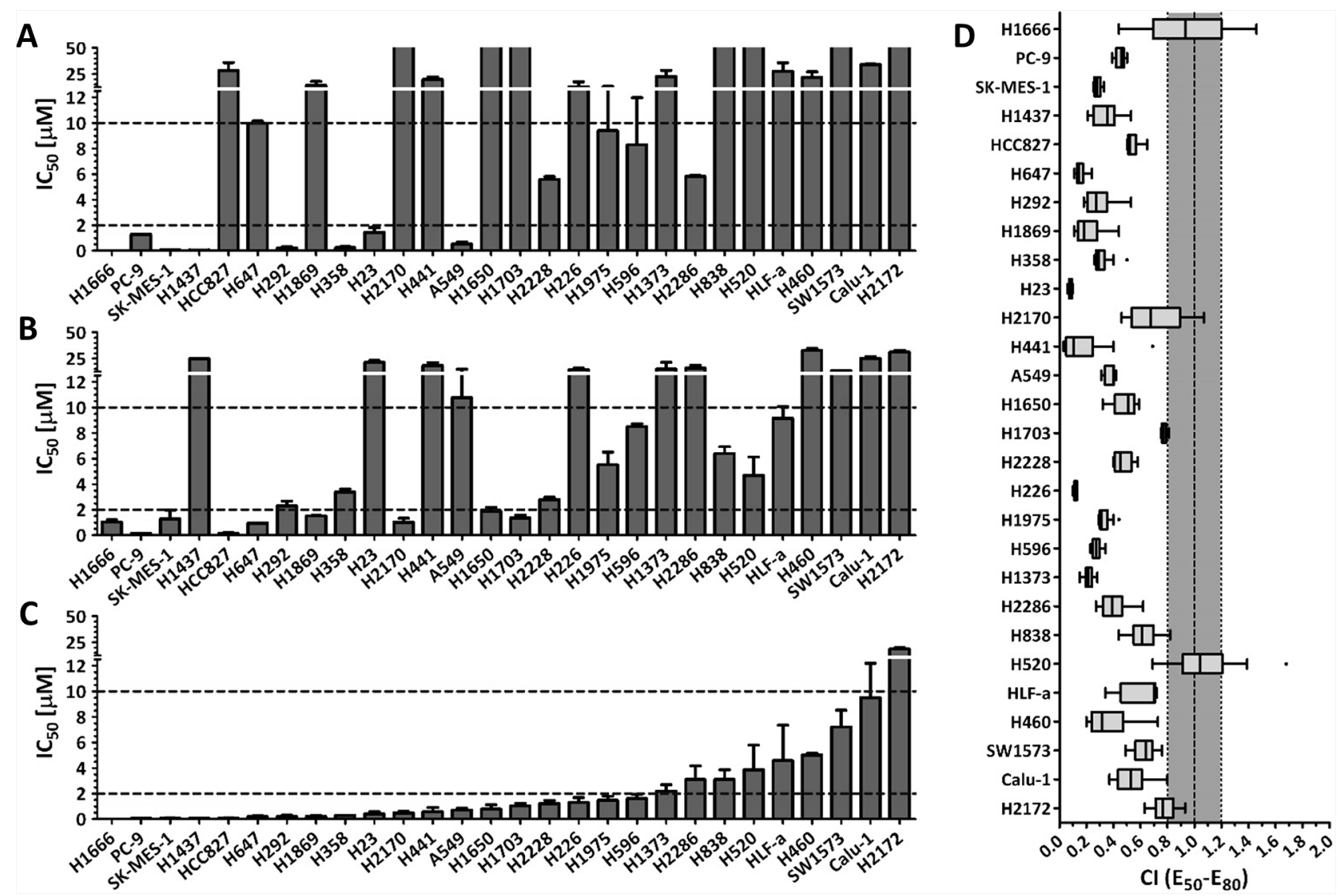

Figure 1: The combination of MEK inhibitor PD0325901 with SRC inhibitor Saracatinib promoted synergistic inhibition of cell growth in NSCLC cell lines. Cell proliferation $\mathrm{IC}_{50}$ plots $(\mathrm{mean} \pm \mathrm{SD})$ for a panel of $28 \mathrm{NSCLC}$ cell lines treated with PD0325901 A. Saracatinib B. or at a fixed PD0325901 to Saracatinib ratio of 0.25:1 C. for 72 h. Data were tabulated from three independent experiment sets. $\mathrm{IC}_{50}<2 \mu \mathrm{M}$ indicates cell lines are sensitive to drug (lower dotted line), $\mathrm{IC}_{50}>10 \mu \mathrm{M}$ indicates cell lines are insensitive to drug (upper dotted line). D. combination index (CI) box plots of PD0325901 and Saracatinib co-treatment at the ratio of $0.25: 1$ on the cell line panel. Combination index of $\mathrm{CI}<0.8$ indicates synergism, CI from 0.8 to 1.2 indicates additive effect, and CI $>1.2$ indicates antagonism.

in drug combination studies $[10,11,14,18]$. We observed that PD:AZ at $0.25: 1$ ratio was the optimal drug ratio for most of the tested cell lines, as the combination ratio tend to generate more synergistic CI values (Supplemental Fig. 2). We observed that when PD:AZ at 0.25:1 combination was screened against the cell lines, 19 cell lines $(68 \%)$ were now found to be sensitive, and only 1 cell line (4\%) remained resistant to this combination (Fig. 1C). We also observed that the drug combination performed synergistically on 26 cell lines $(\mathrm{CI}<0.8)$, with strong synergism observed on 17 cell lines $(\mathrm{CI}<0.5)$ (Fig. 1D).

\section{PD0325901 and Saracatinib induced \\ Mesenchymal-Epithelial transition in Snail1 positive NSCLC lines}

To further our investigation on whether PD0325901, Saracatinib and their combination treatment could induce MET, we selected 6 cells lines (Calu-1, H23, H358, H460, H838 and H1373) which exhibited positive basal EMT transcription factor Snaill expression. In addition,
PD0325901 and Saracatinib combination treatment had presented good synergism on these cell lines (Fig. 1D and Supplemental Fig. 2). Subsequent in vitro combination studies on these cell lines will be tested at the PD:AZ optimal drug ratio of $0.25: 1$, as observed previously.

We first demonstrated that MEK inhibition by PD0325901 at $1 \mu \mathrm{M}$ can potently nullify the phosphorylation of its immediate downstream target ERK1/2 in these cell lines (Fig. 2). Likewise, we showed that SRC inhibition by Saracatinib at $4 \mu \mathrm{M}$ was able to down-regulate phosphorylation of SRC at Y416 and its immediate downstream targets FAK at Y861 and PXN at Y118. We also validated the target selectivity of these two compounds whereby individually, they could not down-regulate the phosphorylation of each other's target signaling proteins. These results highlighted the potential advantage of using highly selective compounds in combinations, whereby modulation of specific targets can be customized with different drug combination.

We next showed that MET can be effected by both PD0325901 and Saracatinib in NSCLC cell lines (Fig. 2). 


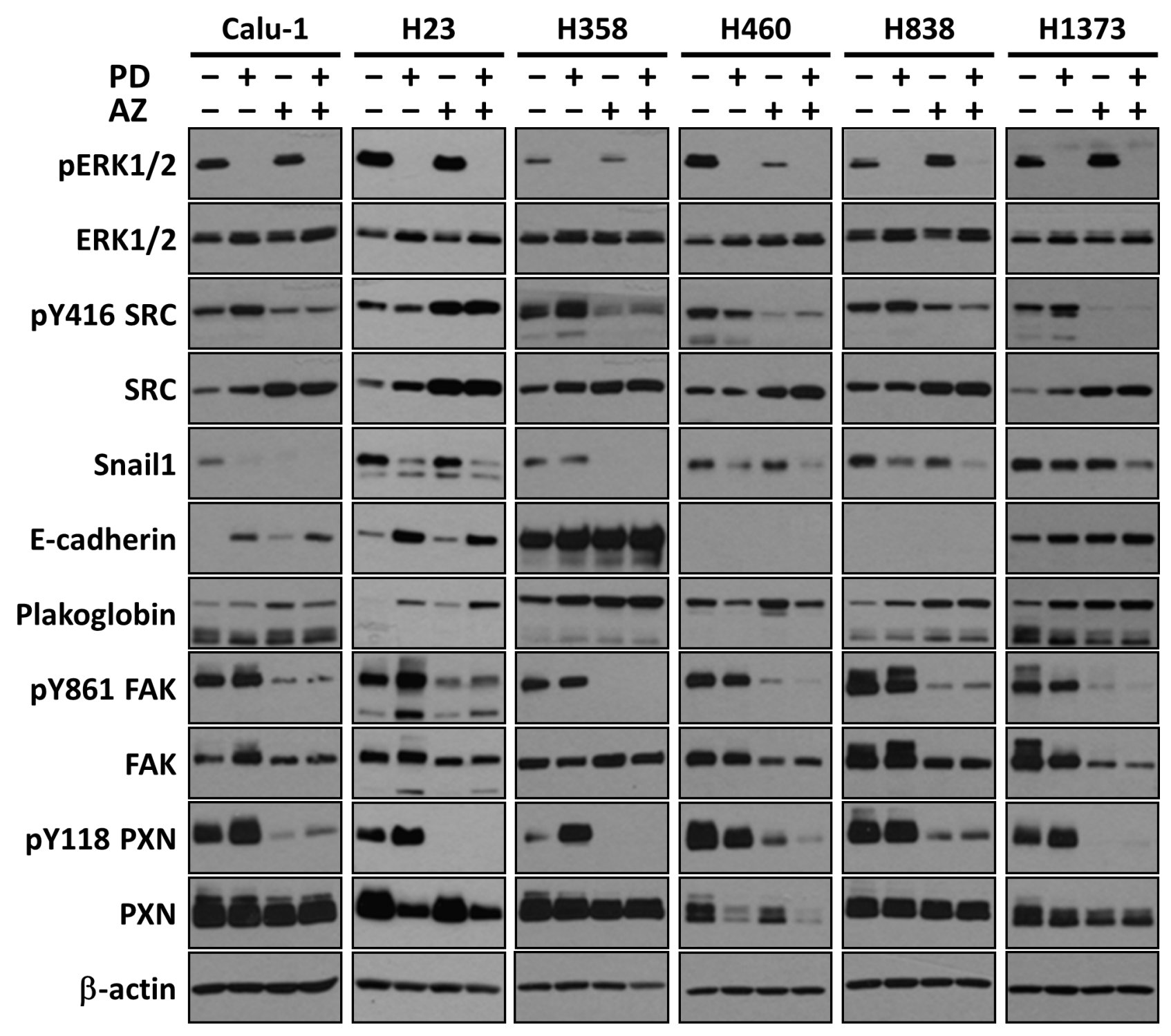

Figure 2: PD0325901, Saracatinib and the combination treatment induced MET in Snail1 positive NSCLC lines. Representative Westernblot images showing the effects of PD $(1 \mu \mathrm{M}), \mathrm{AZ}(4 \mu \mathrm{M})$ and their combination treatment on inhibiting the direct targets ERK and SRC, and modulating EMT-related protein markers (E-cadherin and Plakoglobin epithelial markers; and Snaill, FAK and PXN mesenchymal markers). $\beta$-actin shown as loading control.

We observed that different cell lines exhibit different degrees of MET response against the two compounds individually. For example, PD0325901 induced a stronger down-regulation of Snail1 in H838 as compared to H358 line, while Saracatinib induced a stronger Snaill down-regulation in H358 compared to H838. Similar observations were also found when comparing the individual drug induced E-cadherin changes between Calu-1 and H1373 lines. Overall, we consistently observed a down-regulation of Snaill expression, in concordance with the up-regulation of both E-cadherin and Plakoglobin epithelial markers in the drug treated samples compared to untreated control, indicative of MET induction [19]. Interestingly, we observed that the drug combination together can complementarily enhance MET induction, increasing both E-cadherin and Plakoglobin expression, and further reducing Snail1, FAK and PXN expression in the cell lines, compared to the single drug treated conditions.

\section{PD0325901 and Saracatinib increased}

E-cadherin and Plakoglobin expression and localization at the cell-cell contacts

We conducted immunofluorescence staining experiments to further analyze the MET induction response through quantifying and comparing the functional expression and localization of E-cadherin (Fig. 3A) and Plakoglobin (Fig. 3B) in untreated and drug treated $\mathrm{H} 358$ and $\mathrm{H} 1373$ cell lines. 
Morphologically, we immediately observed that the drug treated cells exhibited increased cell compactness compared with untreated cells. Consistent with the findings above, we observed that both PD0325901 and Saracatinib single treatments could increase E-cadherin and Plakoglobin expression, with drug combination treatment showing the most significant increase in expression levels (E-cadherin $1.92 \pm 0.30$ fold and Plakoglobin $1.49 \pm 0.13$ fold in H358 line; E-cadherin $1.68 \pm 0.17$ fold and Plakoglobin $1.62 \pm 0.17$ fold in H1373 line), compared to untreated controls. We also observed that both PD0325901 and Saracatinib single treatments and the drug combination treatment to an even greater extent could induce a higher degree of localization of E-cadherin and Plakoglobin at the cellcell contacts, as compared to controls.

\section{MET induction by PD0325901 and Saracatinib reduced cell migratory and invasive behavior}

We further performed cell migration (scratch) assays and Boyden chamber Matrigel invasion assays on these cell lines to determine whether the MET induction by PD0325901 and Saracatinib could promote a functional response by limiting the cell migratory and invasive behavior. Both PD0325901 and Saracatinib induced
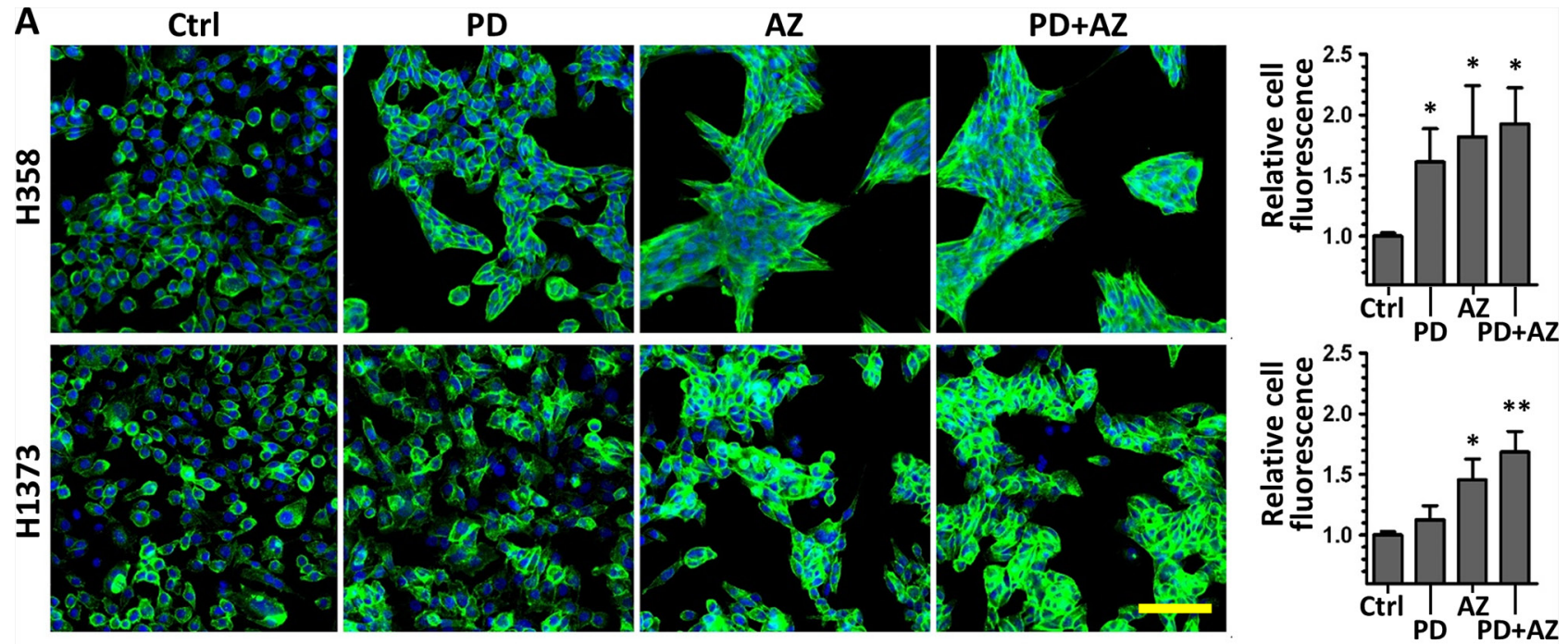

B

Ctrl

PD

$A Z$
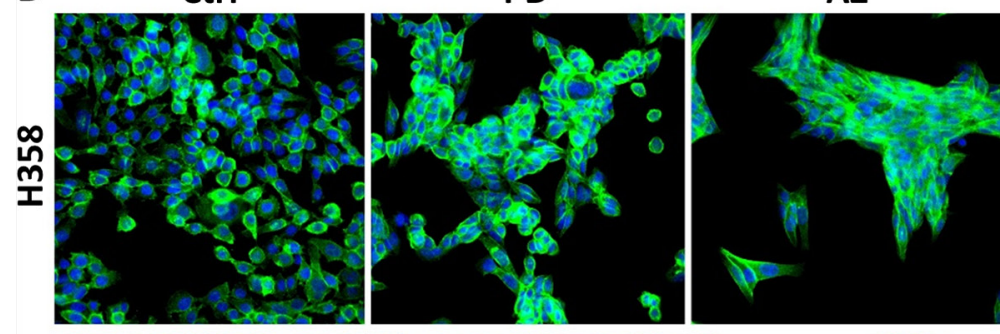

$P D+A Z$
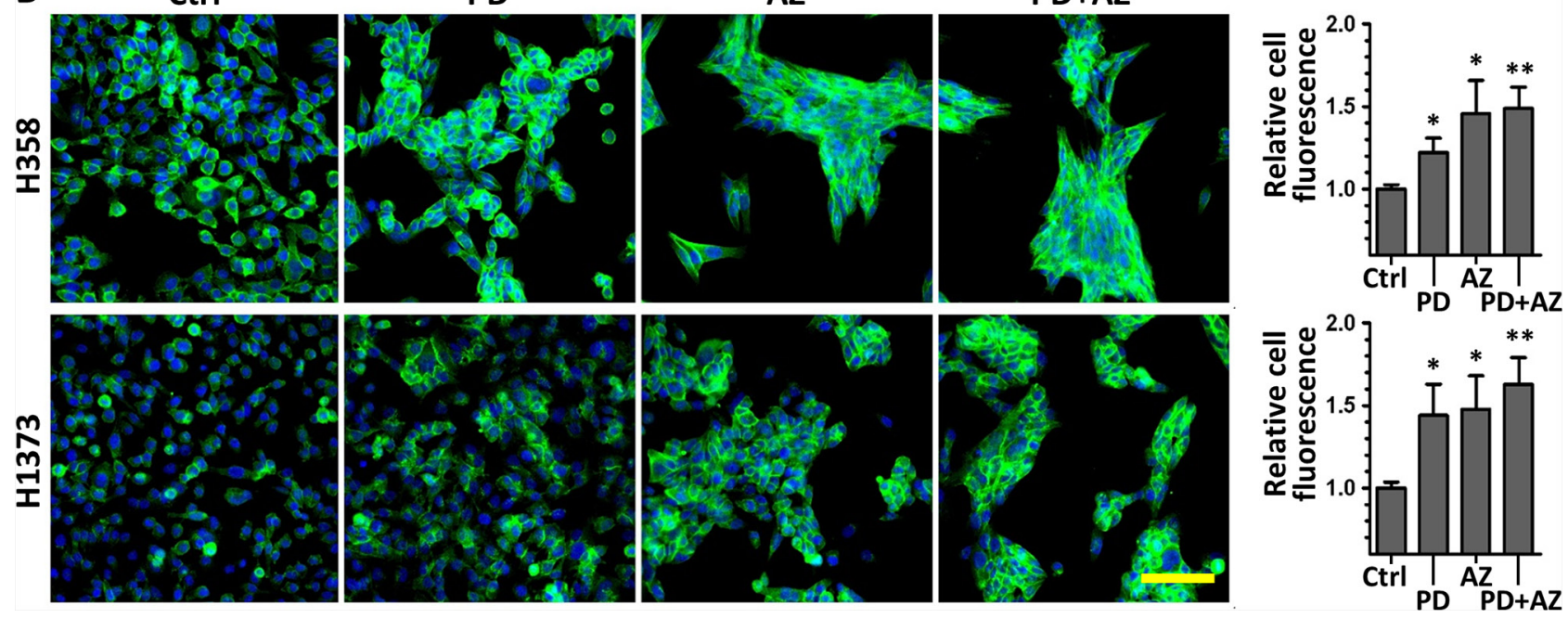

Figure 3: PD0325901, Saracatinib and the combination treatment increased epithelial markers E-cadherin and Plakoglobin expression and localization at the cell-cell contacts. H358 and H1373 were treated with DMSO control (Ctrl), or with PD $(1 \mu \mathrm{M}), \mathrm{AZ}(4 \mu \mathrm{M})$ or their combination for $48 \mathrm{~h}$ to induce MET. E-cadherin or Plakoglobin immunofluorescence imaging was performed and the cell fluorescence for each marker was quantified. A. representative images of E-cadherin stained cells (green) under various drug treated conditions. B. representative images of Plakoglobin stained cells (green) under various drug treated conditions. Cell nuclei were counterstained with Hoechst 33342 (blue). Scale bar: $100 \mu \mathrm{m}$. Graphs show the relative cell fluorescence intensity (mean \pm SD) of each treated group compared to the control group, calculated from at least three independent experiments. ${ }^{*}, P<0.05 ; * *, P<0.01$ compared with Ctrl group. 
MET were able to significantly reduce the cell migratory behavior of the cell lines compared with untreated controls (Fig. 4A; Fig. 4B). In particular, we observed that Saracatinib treatment itself was very effective in reducing cell migration. We attributed this to the fact that Saracatinib potently nullified the phosphorylation of FAK and PXN via disruption of the FAK-SRC-PXN signaling cascade (Fig. 2), and both FAK and PXN played vital roles in cell motility through regulation of focal adhesion dynamics [20]. Interestingly, the combination treatment was observed to be the most effective in further limiting the migratory potential of H23, H358 and H1373 cell lines.

For invasion assay, Matrigel-invasive cell lines Calu-1, H23 and H838 were tested (Fig. 4C; Fig. 4D). We observed that both PD0325901 and Saracatinib induced MET were effective in reducing the cell invasive behavior of these cell lines, despite exhibiting differential antiinvasive sensitivity in response to either of the drug. Nevertheless, the combination treatment was shown to be the most potent in abrogating cell invasion in these cell lines $(0.06 \pm 0.04$ for Calu- $1,0.07 \pm 0.04$ for $\mathrm{H} 23$ and $0.12 \pm 0.05$ for $\mathrm{H} 838$, relative to their respective untreated controls). These functional studies highlighted the complementary inhibitory effects of the PD0325901 / Saracatinib combination treatment.

\section{PD0325901 and Saracatinib exerted predominantly cytostatic growth arrest in NSCLC lines}

We next investigated on how cell cycle progression was regulated by PD0325901 and Saracatinib in these NSCLC lines. Cell-cycle analysis from Propidium Iodide staining experiments indicated that both PD0325901 and Saracatinib exerted predominantly cytostatic effect and induced significant G1-phase accumulation in the cell lines (Fig. 5A; Fig. 5B). In particular, we observed that PD0325901-treated cells in general exhibited a very strong G1-phase accumulation and S-phase depletion as compared with Saracatinib-treated cells. Interestingly, PD0325901 and Saracatinib combination treatment were observed to maintain or further augment the G1-phase accumulation in the cell lines tested.

\section{PD0325901 and Saracatinib combination suppressed anchorage-independent colony growth in NSCLC lines}

For the cell lines (Calu-1, H23, H460 and H1373) that were able to grow under anchorage-independent conditions in soft agar assays (Supplemental Fig. 3), we observed that Saracatinib treatment alone can only modestly inhibit colony growth, with only Calu-1 responding with $\mathrm{IC}_{50}<1 \mu \mathrm{M}$. PD0325901 treatment alone, on the other hand, was potent in reducing anchorage-independent colony growth, with all cell lines responding with $\mathrm{IC}_{50}<1 \mu \mathrm{M}$ (Supplemental Table $1)$. This correlates with the strong cytostatic growth arrest effect exerted by PD0325901 in the NSCLC lines, as shown previously (Fig. 5A). The PD0325901 and Saracatinib combination treatment was also effective in suppressing anchorage-independent colony growth. Interestingly, we analyzed that the combination treatment can substantially reduce the effective $\mathrm{IC}_{50}$ of Saracatinib, without increasing the effective $\mathrm{IC}_{50}$ of PD0325901 in the combination. The drug combination was also observed to act mostly synergistically on Calu-1, H23 and H460 and additively on H1373.

\section{PD0325901 and Saracatinib delayed tumor growth and induced E-cadherin expression in xenograft tumors}

We evaluated the single and combinatorial effects of PD0325901 and Saracatinib co-treatment in vivo in H460 and H358 xenograft models, using doses previously documented to result in therapeutically-relevant concentrations [21, 22]. Tumors-bearing mice were randomized and administered with vehicle control, PD0325901 or Saracatinib alone, or with PD0325901 / Saracatinib combination. H460 and H358 tumors in the vehicle control group grew rapidly during the course of the experiment, reaching $29.6 \pm 7.2$ and $13.6 \pm$ 5.8 tumor volume fold change respectively at assay end point. Saracatinib treatment alone resulted in moderate delay in both H460 and H358 tumor growth (21.7 \pm 3.0 and $10.8 \pm 8.5$ tumor volume fold change respectively), while PD0325901 alone or combination treatments resulted in substantial tumor growth inhibition in H460 tumors (7.10 \pm 1.5 and $7.20 \pm 2.0$ tumor volume fold change respectively) and tumor regression in $\mathrm{H} 358$ tumors $(0.95 \pm 0.33$ and 1.07 \pm 0.29 tumor volume fold change respectively) (Fig. 6A; Fig. 6B; Fig. 6C). Minimal weight loss was observed in the mice in all treatment groups, suggesting that this combination strategy was well-tolerated (data not shown).

We observed through immunohistochemistry staining that E-cadherin expression was significantly induced in the H460 tumors treated with PD0325901 or Saracatinib, compared with vehicle control. Interestingly, the PD0325901 / Saracatinib combination treatment also induced a moderately higher induction of E-cadherin, compared with the single drug treatments (Fig. 6D; Fig. 6E). We further confirmed from the whole tumor lysates that E-cadherin expression was increased in PD0325901, Saracatinib and drug combination treated tumors, compared with vehicle control (Fig. 6F).

\section{DISCUSSION}

The present study shows that SRC and MEK co-inhibition by Saracatinib and PD0325901 respectively can be broadly effective in tumor growth control of a wide panel of NSCLC cell lines. In addition, 


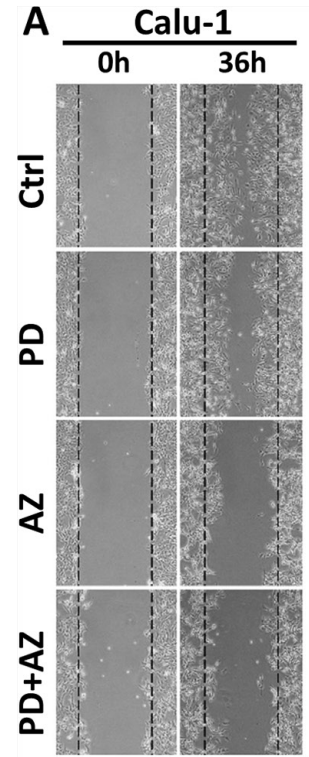

B

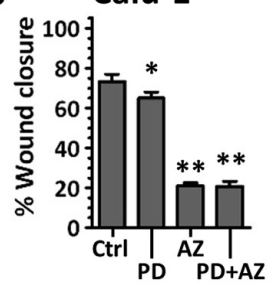

C
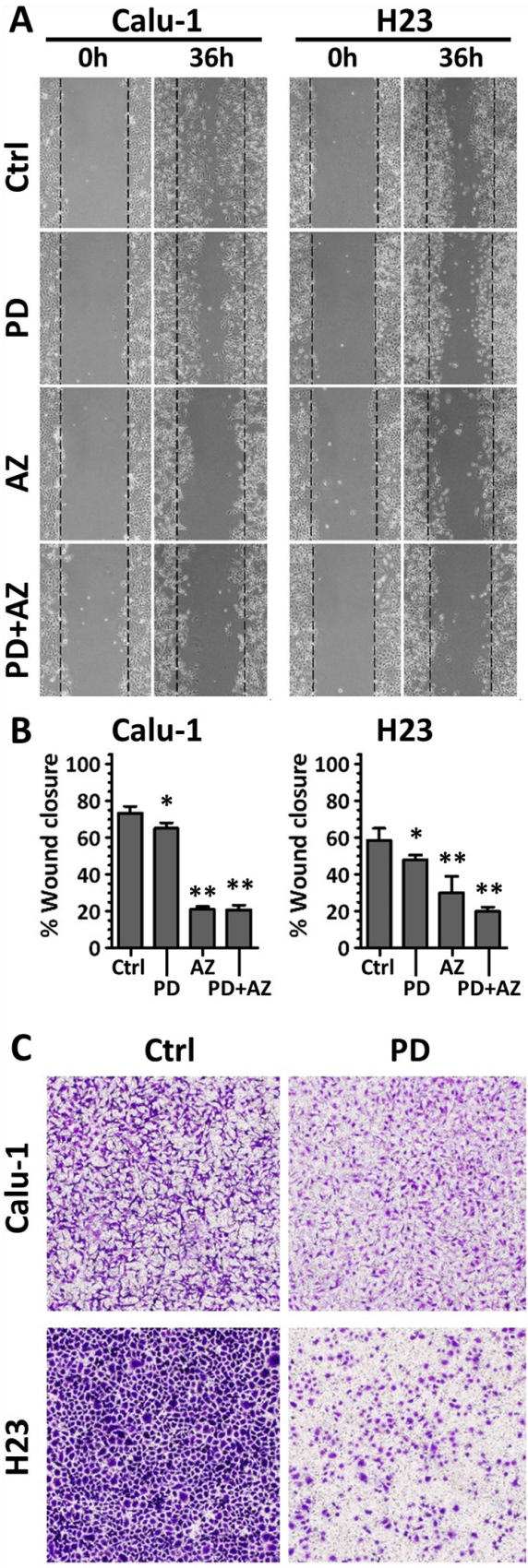

H23

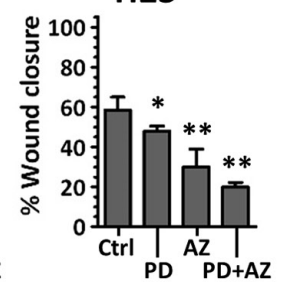

PD
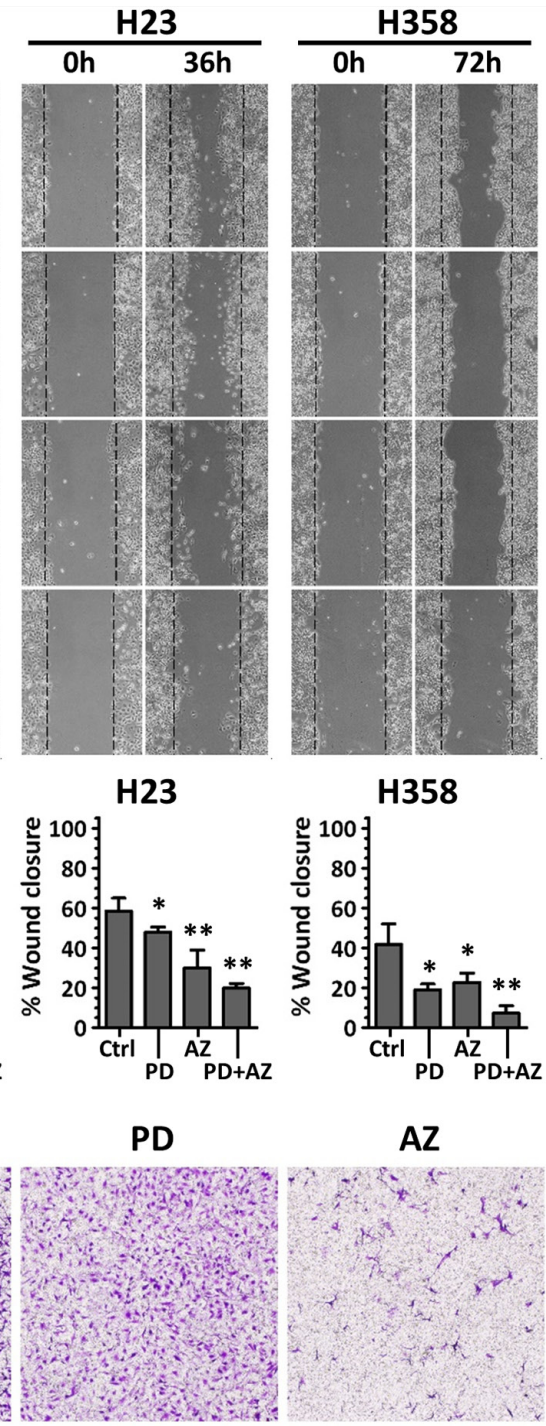

H358

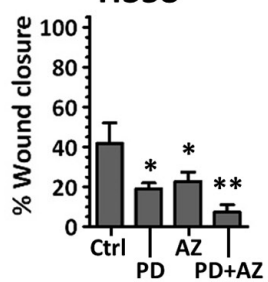

AZ
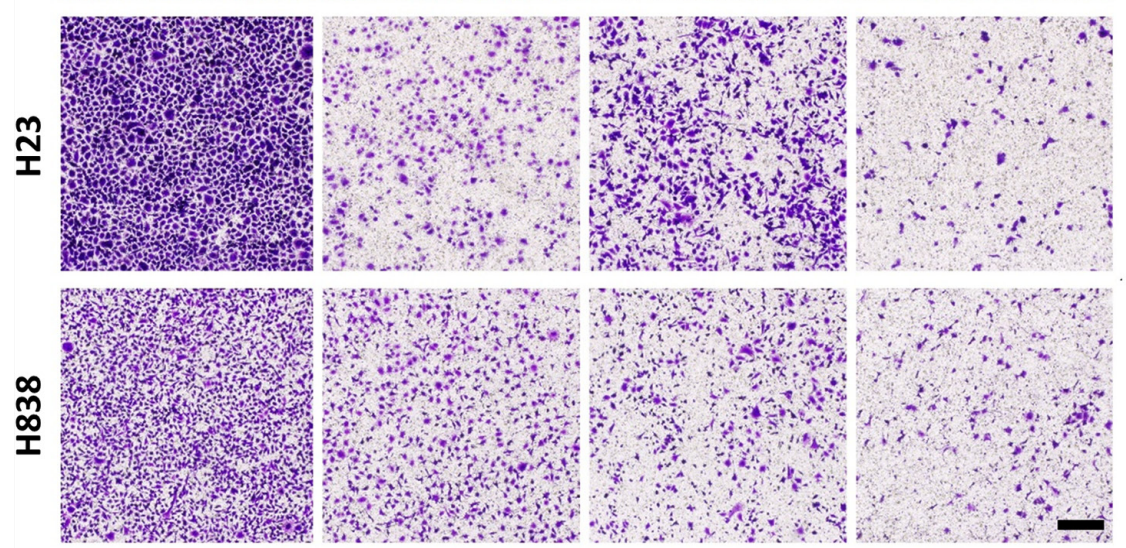
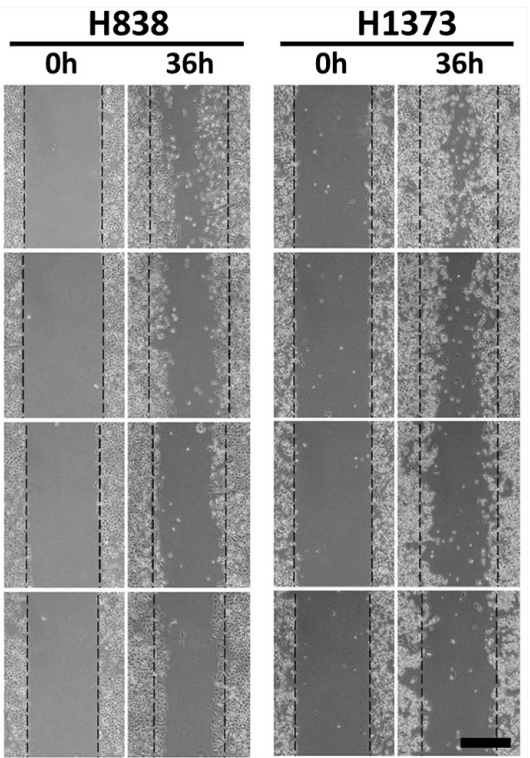

H1373
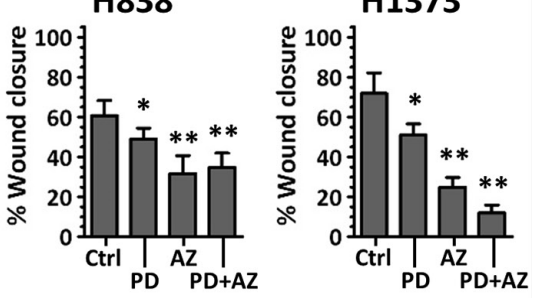

PD+AZ
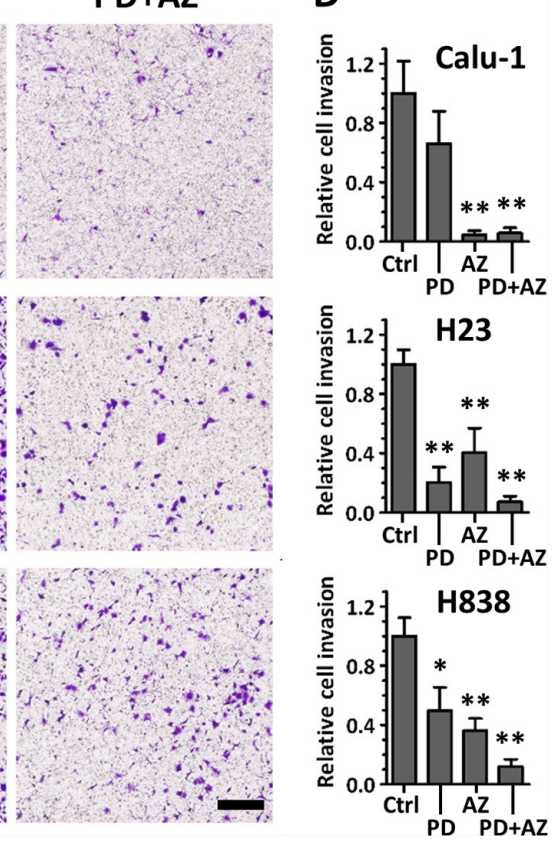

Figure 4: PD0325901 and Saracatinib and the combination treatment reduced cell migratory and invasive activity. Cell lines were treated with DMSO control (Ctrl), or with $\mathrm{PD}(1 \mu \mathrm{M})$, AZ $(4 \mu \mathrm{M})$ or their combination. A. for cell migration assays, the wounded areas were imaged at $0 \mathrm{~h}$ and 36 or $72 \mathrm{~h}$ after the monolayer cultures were scratched. Scale bar: $500 \mu \mathrm{m}$. B. the gap area of each image was measured, and the wound closure percentages (mean \pm SD) were calculated from at least three independent experiments. C. for Boyden chamber Matrigel invasion assays, cells that invaded through to the underside of the transwell filter after $48 \mathrm{~h}$ incubation under various drug treated conditions were fixed, crystal violet stained and imaged. Scale bar: $250 \mu \mathrm{m}$. D. cell count analysis was performed for each image and the relative cell invasion (mean $\pm \mathrm{SD}$ ) of each treated group compared to the Ctrl group of each cell line was calculated from at least three independent experiments. ${ }^{*}, P<0.05 ;{ }^{* *}, P<0.01$ compared with Ctrl group. 


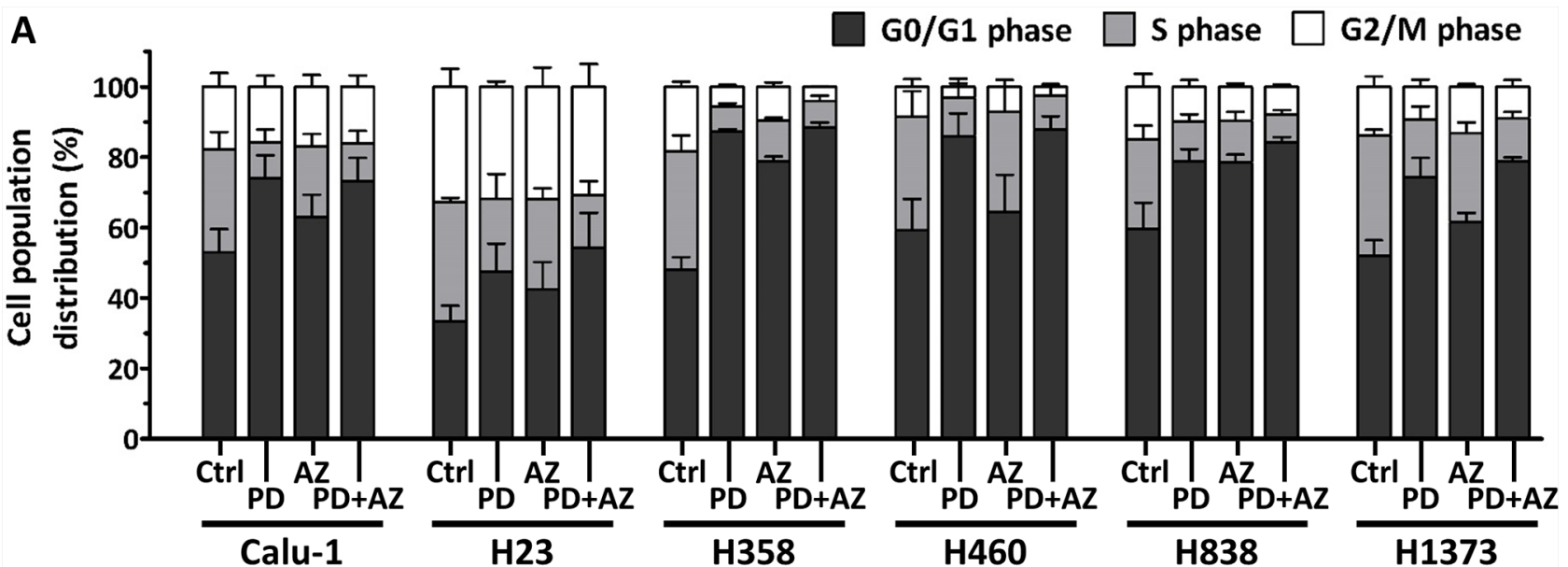

B

\begin{tabular}{|c|c|c|c|c|c|c|c|}
\hline & & \multicolumn{2}{|c|}{ G1 } & \multicolumn{2}{|c|}{$\mathbf{S}$} & \multicolumn{2}{|c|}{ G2 } \\
\hline & & Mean \pm SEM & $p$-value & Mean \pm SEM & $p$-value & Mean \pm SEM & $p$-value \\
\hline \multirow{4}{*}{ Calu-1 } & Ctrl & $52.99 \pm 6.58$ & & $29.34 \pm 4.80$ & & $17.67 \pm 3.90$ & \\
\hline & PD & $74.05 \pm 6.53$ & 0.0039 & $10.23 \pm 3.60$ & 0.0009 & $15.73 \pm 3.23$ & 0.4722 \\
\hline & $A Z$ & $63.02 \pm 6.38$ & 0.0711 & $20.12 \pm 3.46$ & 0.0235 & $16.86 \pm 3.36$ & 0.7635 \\
\hline & $P D+A Z$ & $73.15 \pm 6.68$ & 0.0051 & $10.87 \pm 3.42$ & 0.0011 & $15.98 \pm 3.26$ & 0.5312 \\
\hline \multirow{4}{*}{$\mathrm{H} 23$} & Ctrl & $33.4 \pm 4.43$ & & $33.82 \pm 1.23$ & & $32.78 \pm 5.09$ & \\
\hline & PD & $47.45 \pm 8.03$ & 0.0132 & $20.76 \pm 7.05$ & 0.0134 & $31.79 \pm 1.51$ & 0.6945 \\
\hline & $A Z$ & $42.54 \pm 7.69$ & 0.0582 & $25.58 \pm 2.96$ & 0.0018 & $31.88 \pm 5.48$ & 0.7947 \\
\hline & $P D+A Z$ & $54.36 \pm 9.83$ & 0.0058 & $14.82 \pm 4.00$ & 0.0002 & $30.82 \pm 6.52$ & 0.6106 \\
\hline \multirow{4}{*}{ H358 } & Ctrl & $48.05 \pm 3.55$ & & $33.60 \pm 4.54$ & & 18.351 .43 & \\
\hline & PD & $87.21 \pm 0.72$ & 0.0001 & $7.28 \pm 0.77$ & 0.0011 & $5.51 \pm 0.55$ & 0.0001 \\
\hline & $A Z$ & $78.76 \pm 1.43$ & 0.0001 & $11.64 \pm 0.82$ & 0.0019 & $9.60 \pm 1.23$ & 0.0001 \\
\hline & $P D+A Z$ & $88.45 \pm 1.44$ & 0.0000 & $7.47 \pm 1.52$ & 0.0006 & $4.08 \pm 0.21$ & 0.0002 \\
\hline \multirow{4}{*}{ H460 } & Ctrl & $59.27 \pm 8.83$ & & $32.18 \pm 7.37$ & & $8.55 \pm 2.18$ & \\
\hline & PD & $86.02 \pm 6.43$ & 0.0035 & $10.87 \pm 5.45$ & 0.0043 & $3.11 \pm 1.00$ & 0.0094 \\
\hline & $\mathrm{AZ}$ & $64.46 \pm 10.55$ & 0.4797 & $28.42 \pm 9.09$ & 0.5454 & $7.11 \pm 1.98$ & 0.3680 \\
\hline & $P D+A Z$ & $87.83 \pm 3.83$ & 0.0038 & $9.67 \pm 3.16$ & 0.0047 & $2.51 \pm 0.77$ & 0.0077 \\
\hline \multirow{4}{*}{ H838 } & Ctrl & $59.57 \pm 7.57$ & & $25.48 \pm 3.95$ & & $14.95 \pm 3.69$ & \\
\hline & PD & $78.90 \pm 3.47$ & 0.0086 & $11.22 \pm 2.06$ & 0.0020 & $9.88 \pm 1.89$ & 0.0641 \\
\hline & $A Z$ & $78.51 \pm 2.22$ & 0.0119 & $11.82 \pm 2.54$ & 0.0020 & $9.67 \pm 0.92$ & 0.0605 \\
\hline & $P D+A Z$ & $84.24 \pm 1.49$ & 0.0062 & $7.85 \pm 1.30$ & 0.0016 & $7.90 \pm 0.61$ & 0.0298 \\
\hline \multirow{4}{*}{ H1373 } & Ctrl & $52.08 \pm 4.35$ & & $34.17 \pm 1.56$ & & $13.75 \pm 2.99$ & \\
\hline & PD & $74.44 \pm 5.41$ & 0.0008 & $16.31 \pm 3.72$ & 0.0009 & $9.25 \pm 2.03$ & 0.0525 \\
\hline & $A Z$ & $61.55 \pm 2.63$ & 0.0140 & $25.32 \pm 3.02$ & 0.0047 & $13.13 \pm 0.77$ & 0.7136 \\
\hline & $P D+A Z$ & $78.87 \pm 1.11$ & 0.0007 & $12.26 \pm 1.74$ & 0.0000 & $8.87 \pm 1.93$ & 0.0395 \\
\hline
\end{tabular}

Figure 5: PD0325901 and Saracatinib and the combination treatment primarily exerted G1-phase cell cycle arrest in NSCLC lines. Cell cycle analysis was performed on cell lines after treatment with DMSO control (Ctrl), or with PD, AZ or their combination for $48 \mathrm{~h}$. Graph A. and table B. show the cell cycle distribution (mean \pm SD) of each treatment group, calculated from at least three independent experiments. Statistical analyses were performed on treated groups as compared with Ctrl group.

we show that PD0325901 and Saracatinib are potent EMT modulators and both are effective in inducing a MET response in Snaill positive NSCLC cell lines. Furthermore, we demonstrate that the co-inhibition of SRC and MEK pathways results in a MET phenotype that is accompanied by a decrease in Snaill and an increase in E-cadherin expression with low cell migratory ability. These data provide proof-of-concept for the use of PD0325901 and Saracatinib in combination to combat invasive growth in NSCLC.

The activation of the SRC kinase is known to promote the activity of angiogenesis, proliferation, 

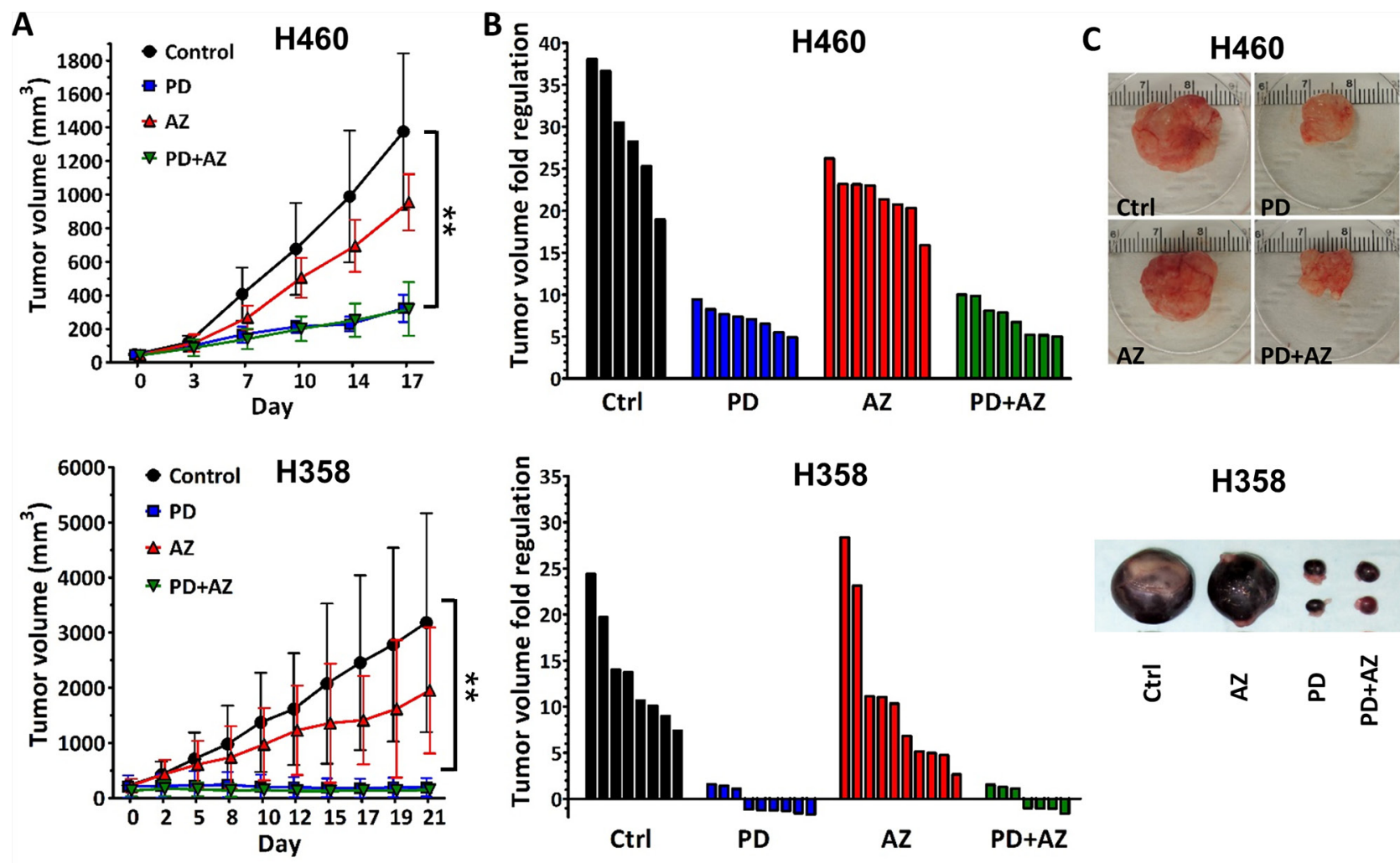

H358

H358

D
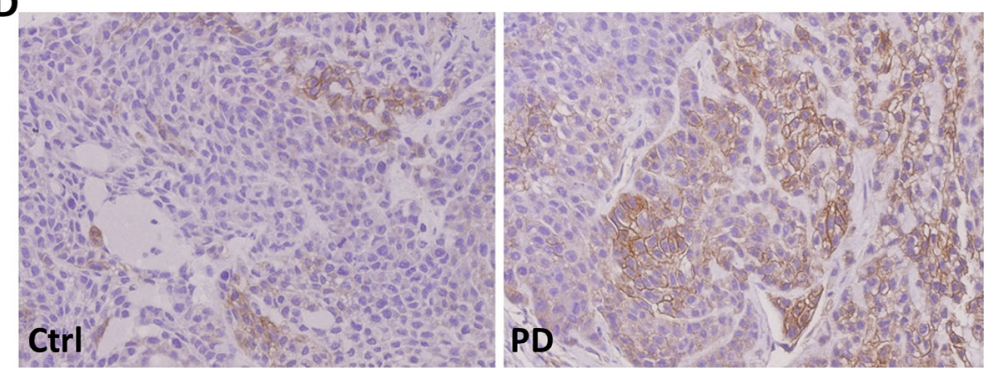

E
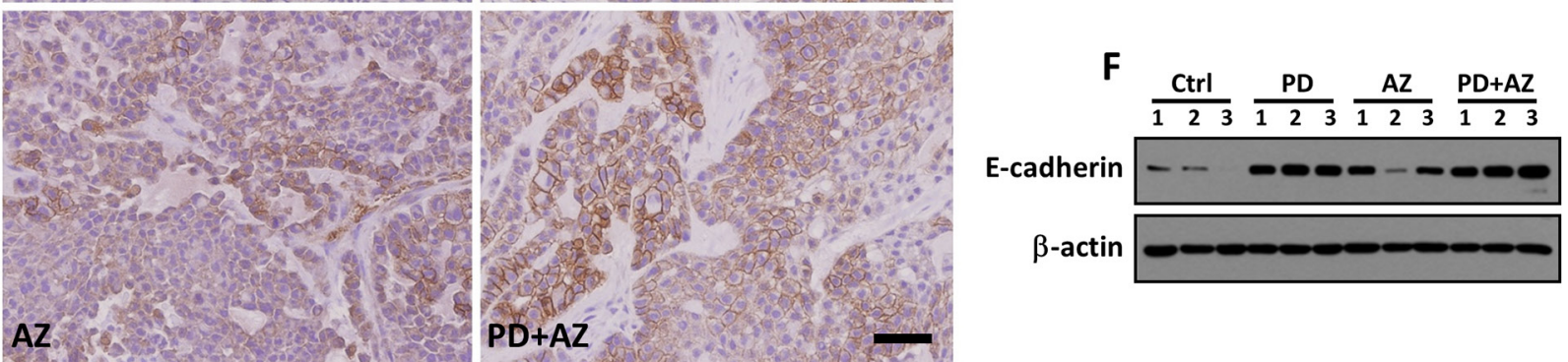

Figure 6: Inhibition of tumor growth and induction of E-cadherin expression in xenograft tumors by PD0325901 or Saracatinib treatment alone or in combination. $\mathrm{H} 460$ and $\mathrm{H} 358$ cells were subcutaneously implanted into the flanks of nude mice. Treatment was started when average tumor volume reached $50 \mathrm{~mm}^{3}$ (for H460) or $200 \mathrm{~mm}^{3}$ (for H358) in size. Vehicle control only (Ctrl), PD (12.5 mg/kg), AZ (50 mg/kg) or their combination was administered daily. A. tumor volumes were measured biweekly and data were expressed as mean $\pm \mathrm{SD}$ of 6 to 8 tumors per group. $P<0.01$ compared with Ctrl group. B. waterfall plots showing the tumor volume fold regulation (relative to initial tumor volume) for the individual tumors in each treatment group after 17 days treatment. C. images of representative $\mathrm{H} 460$ and $\mathrm{H} 358$ tumors from each treatment group. D. E-cadherin expression levels were also assessed in the $\mathrm{H} 460$ tumors by IHC. Representative examples were shown. Scale bar: $50 \mu \mathrm{m}$. E. E-cadherin expression in the IHC images of H460 tumors was analyzed by quantifying the number of E-cadherin-positive cells (brown) compared to the total cells. Bar graph showing the mean percentage of E-cadherin-positive cells \pm SD of 3 tumors per group. ${ }^{*}, P<0.05 ;{ }^{* *}, P<0.01$ compared with Ctrl group. $\mathbf{F}$. westernblot showing relative E-cadherin expression of whole tumor lysates for each treatment group of $\mathrm{H} 460$ tumor ( $n=3$ per group). $\beta$-actin shown as loading control. 
survival and invasion pathways, which leads to the aberrant growth of tumors. The active SRC pathway has also been documented in upwards of $50 \%$ of tumors derived from several cancers, including NSCLC [23]. Therefore, this potential target has been extensively investigated in NSCLC, and over the past decade, several clinical studies have evaluated the use of selective SRC inhibitors such as Saracatinib for treating NSCLC [24-27]. However, although Saracatinib was well tolerated in cancer patients and reduction in tumor SRC activity was observed in phase I trial [24], it was later shown to be ineffective as single agent therapy, as objective responses to Saracatinib were not observed in phase II trials in NSCLC [25] as well as other cancers [26, 27]. Our in vivo experiments also confirmed that Saracatinib treatment alone only resulted in modest growth delay with no tumor shrinkage (Fig. 6).

Likewise, the MAPK signaling cascade also plays critical roles in the regulation of cell proliferation, survival, differentiation, motility, and angiogenesis. It serves a pivotal role in oncogenesis and growth of transformed cells, and investigations on blocking the MAPK pathway via MEK inhibitors such as PD0325901 have come to the forefront as an exciting approach in cancer therapeutics [28]. However, although PD0325901 demonstrated antitumor activity in preclinical xenograft models [29] and preliminary clinical activities on melanoma and NSCLC patients in phase I trial [30], the phase II study on patients with advanced NSCLC failed to show any objective responses [31]. Due to lack of responses coupled with the safety issues, current studies focus on PD0325901 schedule and the use of rational combination strategies [31, 32]. Our study suggests that SRC and MEK co-inhibition by Saracatinib and PD0325901 can be a proof-of-concept treatment strategy since the combination acts mostly synergistically in inhibiting cell proliferation across a wide panel of NSCLC cell lines (Fig. 1). In addition, we show that PD0325901 can be co-administered at a lower dose ratio compared to Saracatinib, which may circumvent the dose safety issues related to PD0325901.

The role of EMT as one of the important nongenetic mechanisms that drives tumor cell dissemination and drug ineffectiveness to cancer therapy has been intensively researched [12-15]. The extent of EMT across various cancers has recently been reported to vary widely, highlighting the heterogeneity of cancers [33]. We hypothesize that treatments that modulate the EMT status of tumors towards a more defined state (i.e. epithelial state) may reduce the metastatic aggressiveness of the cancer and make the tumors more susceptible to conventional chemotherapy. It is well-accepted that a repertoire of dysregulated signaling pathways is responsible for the induction of EMT in cancers [34-36]. In addition, the development in targeted therapeutics to treat pathways driven cancers have rapidly revolutionized anti-cancer therapies [37, 38]. However, the EMT modulating properties of many clinically tested targeted drugs have not been validated in human cancers. Our previous high-throughput screening study to identify EMT modulators had uncovered several targeted compounds (PD0325901 and Saracatinib among them) that could potently interfere with growth factor induced EMT signaling [14]. In this study, we further validate that both PD0325901 and Saracatinib are potent EMT modulators and individually, each compound can differentially induce a MET response in Snaill positive NSCLC cell lines. Although the mechanisms driving these differential MET still remains to be elucidated, overall, we show that the PD0325901 and Saracatinib combination can effectively be used in combination to strongly drive cancer cells towards a more epithelial state through up-regulation of E-cadherin across most of the NSCLC lines tested. This is consistent with findings by two other groups whereby inhibiting both SRC and MEK signaling suppressed the invasive growth and cellular survival of tumor cells $[39,40]$. Importantly, we verified that high E-cadherin expression is associated with poor migratory activity in NSCLC cells (Supplemental Fig. 4A; 4C). Although there are controversial reports that show a correlation between high E-cadherin expression with aggressive and metastatic growth in breast and ovarian tumors, the differential impact of E-cadherin expression on invasive growth in different organ types needs further investigation [41, 42]. Furthermore, we show that the high E-cadherin expression did not activate other reciprocal pathways like AKT and MAPK signaling pathway (Supplemental Fig. 4B; 4D). This suggests that PD0325901 and Saracatinib combination serves as a favorable therapeutic strategy that induce MET in NSCLC cells yet overcoming the activation of reciprocal pathways prevalent in drug resistance.

In conclusion, we demonstrate through biomarker expression and functional studies that MET can be enhanced in NSCLC lines when PD0325901 and Saracatinib are used in combination. We also demonstrate that PD0325901 synergized with Saracatinib co-treatment to reduce cell proliferation and tumorigenicity in NSCLC lines. These data support further preclinical and clinical development of combining SRC and MAPK pathways inhibition to treat advanced stage NSCLC.

\section{MATERIALS AND METHODS}

\section{Cell culture}

All lung carcinoma cell lines except PC-9 were obtained directly from the American Type Culture Collection (ATCC) repository. The PC-9 cell line was a gift from A. Ali (CSI, Singapore). Cell lines were authenticated by DNA short tandem repeats analysis using GenePrint 10 kit (Promega). The cell lines were 
maintained in RPMI-1640 (Nacalai Tesque) growth medium supplemented with $10 \%$ fetal bovine serum (FBS, HyClone, Thermo Scientific), 2 mM L-glutamine (Gibco, Life Technologies) and $100 \mathrm{U} / \mathrm{ml}$ penicillinstreptomycin (Gibco, Life Technologies) at $37^{\circ} \mathrm{C}$ in a $5 \%$ $\mathrm{CO}_{2}$ atmosphere.

\section{Cell proliferation assay and synergism analysis}

Saracatinib (AZ) and PD0325901 (PD) were purchased from Selleck Chemicals. Cells were plated into microtiter culture plates (Greiner) and treated with varying concentrations of $\mathrm{PD}$ or $\mathrm{AZ}$ alone, or drug combinations at fixed $\mathrm{PD}$ to $\mathrm{AZ}$ ratios. After $72 \mathrm{~h}$, cells were lysed with CellTiter-Glo luminescent cell viability assay reagent (Promega) and luminescence was read using a microplate reader (Infinite M200 Pro, Tecan). Percent cell proliferation was calculated relative to DMSO control treated cells.

Sigmoidal dose-response curve fitting for each treatment condition were analyzed using GraphPad Prism 5 software. Drug concentrations that result in cell proliferation inhibition of between $50 \%$ and $80 \%$ (i.e. $\mathrm{IC}_{50}$ to $\mathrm{IC}_{80}$ ) for each treatment condition were then calculated and tabulated for synergism analysis.

Combination index (CI) for PD and AZ combination was calculated based on the Loewe Additivity equation [18]. Briefly, for a cell growth inhibition effect of $E_{y}$ :

where $\mathrm{d}_{\mathrm{PD}}$ and $\mathrm{d}_{\mathrm{AZ}}$ are the respective combination doses of PD and AZ that will achieve $\mathrm{y} \%$ cell growth inhibition effect; $\mathrm{D}_{\mathrm{PD}}$ and $\mathrm{D}_{\mathrm{AZ}}$ are the corresponding single doses for PD and AZ to result in the same effect; and $r$ is the PD:AZ concentration ratio in the drug combination. The CI values for between $50 \%$ to $80 \%$ growth inhibition effect, $\mathrm{CI}\left(\mathrm{E}_{50-80}\right)$, was tabulated for the drug combination treatment on each cell line.

\section{Western blots}

E-cadherin antibody was purchased from BD Biosciences. Plakoglobin and Paxillin (PXN) antibodies were purchased from Millipore. Antibodies against Snail1, mitogen-activated protein kinase (ERK1/2), phospho-p44/42 ERK1/2, SRC, phospho-SRC (pY416), focal adhesion kinase (FAK), phospho-PXN (pY118), phospho-Akt (pS473), $\beta$-actin and HRP-conjugated secondary antibodies were purchased from Cell Signaling Technology. Phospho-FAK (pY861) antibody was purchased from Thermo Scientific.

Cells are grown on 6-well plates and treated with compounds or DMSO as control for $48 \mathrm{~h}$. Cells were rinsed with PBS and lysed with RIPA buffer supplemented with protease / phosphatase inhibitor cocktail (Promega).
Protein concentration was quantified and equalized protein loads were resolved with Bio-Rad SDS-PAGE system using $8 \%$ to $12 \%$ polyacrylamide gels and transferred to PVDF membranes. Immunoblotting were performed with the antibodies listed above and bound antibodies were detected by chemiluminescence using Amersham ECL Prime Western Blotting reagent (GE Healthcare).

\section{Immunofluorescence imaging}

Cells were plated into black, clear bottom 96-well microtiter plates (Greiner). When the cells reach about $50 \%$ confluency, the cultures were then treated with compounds or DMSO as control. After $48 \mathrm{~h}$ treatment, cells were gently rinsed with $\mathrm{PBS}$, fixed with 4\% paraformaldehyde in PBS for $15 \mathrm{~min}$ and permeabilized with ice-cold methanol for $10 \mathrm{~min}$. Samples were then blocked with blocking buffer (2\% FBS, $0.3 \%$ Triton-X in PBS) for $30 \mathrm{~min}$, followed by immunostaining with E-cadherin (1:500) and Plakoglobin (1:500) primary antibodies in blocking buffer overnight at $4^{\circ} \mathrm{C}$. Samples were then incubated with Alexa Fluor 488 secondary antibodies (1:1000, Molecular Probes, Life Technologies) for $2 \mathrm{~h}$ at $25^{\circ} \mathrm{C}$, followed by Hoechst 33342 nuclear staining (1:2000, Sigma) for $15 \mathrm{~min}$. The wells were then washed and kept in PBS. The plates were sealed with aluminum sealing films (Axygen, Fisher Scientific) and stored at $4^{\circ} \mathrm{C}$ prior to fluorescence imaging.

Plates were imaged using a confocal microplate imager (MetaXpress Ultra, Molecular Devices) with $40 \times$ objective, $405 \mathrm{~nm}$ laser / 417-477 nm filter cube configuration for nuclei imaging, and $488 \mathrm{~nm}$ laser / $525 / 50 \mathrm{~nm}$ filter cube configuration for E-cadherin and Plakoglobin imaging. At least 8 sites were imaged for each well. Image sets were analyzed with ImageJ software using an image processing workflow described previously $[14,43]$. Object segmentation was performed and the E-cadherin or Plakoglobin fluorescence intensity of each cell was quantified. Fluorescence intensity of compound treated cells was calculated relative to DMSO control treated cells.

\section{Cell migration assay}

Cells were plated into 6-well plates and grown to confluency. A $200 \mu \mathrm{l}$ pipette tip was used to make linear scratches on the cell monolayer. The wells were then gently washed with media to remove unattached cells and refreshed with culture media containing test compounds or DMSO control. Suitable areas centered on scratch regions with appropriately $0.60-0.75 \mathrm{~mm}$ wound gap, were selected for wound closure observation. Images of selected areas were acquired at $0 \mathrm{~h}$ (T1) and at the end of the cell migration experiment (T2: $36 \mathrm{~h}$ for Calu-1, H23, $\mathrm{H} 838$ and H1373; and $72 \mathrm{~h}$ for H358), using an optical imaging microscope at $4 \times$ magnification (Olympus CKX41/C-5060). The wound gap area for each image 
was measured using ImageJ software. For each T1 and T2 image set, the wound closure percentage was calculated using the formula: $\left(\right.$ Area $_{\mathrm{T} 1}-$ Area $\left._{\mathrm{T} 2}\right) /$ Area $_{\mathrm{T} 1} \times 100 \%$.

\section{Cell invasion assay}

Cell invasion assay was performed using $8 \mu \mathrm{m}$ pore, 24-well format transwell inserts (Corning). Transwell membranes were coated with $0.1 \mathrm{ml}$ of $0.25 \mathrm{mg} / \mathrm{ml}$ matrigel (BD Biosciences) in PBS and incubated overnight at $37^{\circ} \mathrm{C}$. The following day, $40 \times 10^{3}$ cells in $1 \%$ FBS culture media were seeded into each transwell insert, while $0.5 \mathrm{ml}$ of $10 \%$ FBS culture media containing test compounds or DMSO control was added into the lower chambers. Following a 48 $\mathrm{h}$ incubation to allow cell penetration, non-invaded cells in the transwell insert were removed using cotton swab and the invaded cells on the membrane underside were fixed with methanol and stained with $0.1 \%$ crystal violet in PBS and air dried. For each membrane, five non-overlapping brightfield images were acquired with an optical imaging microscope at $4 \times$ magnification (Olympus IX71/DP71). The number of cells in each image was then counted using ImageJ software. Percent cell invasion was calculated relative to DMSO control treated cells.

\section{Cell cycle analysis}

Cell cycle fractions were determined through propidium iodide (PI) nuclear staining. Briefly, cells are grown on 6-well plates and treated with compounds or DMSO as control for $48 \mathrm{~h}$. Cells were then harvested, fixed with $70 \%$ cold ethanol, and stained with PI staining buffer $(0.03 \mathrm{mg} / \mathrm{ml} \mathrm{PI}, 0.1 \mathrm{mg} / \mathrm{ml}$ RNAse A, $0.1 \%$ Triton-X in PBS) for $30 \mathrm{~min}$ at $25^{\circ} \mathrm{C}$. Flow cytometry was performed using BD LSR II flow cytometer (BD Biosciences). At least 10,000 cell events were collected per sample. Cell cycle analysis was performed using FlowJo software (Tree Star).

\section{Anchorage independent assay}

$0.5 \mathrm{ml}$ of cell suspension in $0.36 \%$ agarose containing culture media was plated into each well on the top of existing $0.6 \%$ bottom agarose in 24-well tissue culture plates. $0.5 \mathrm{ml}$ of culture media containing compound or compound combinations at various doses was then loaded into each well. Plates are incubated in a $37^{\circ} \mathrm{C}, 5 \% \mathrm{CO}_{2}$ incubator for a period of $2-4$ weeks to allow cell colonies to grow large enough to be visualized through MTT tetrazolium dye staining. At the assay endpoint, $0.04 \mathrm{ml}$ of $5 \mathrm{mg} / \mathrm{ml}$ MTT solution (Sigma) were added into each well and further incubated at $37^{\circ} \mathrm{C}$ for $3 \mathrm{~h}$. Cell colony images of each well were acquired using a flatbed scanner (Epson). The number of colonies formed in each well was then quantified using ImageJ software. Percent cell colony formation was calculated relative to DMSO control treated cells.

\section{Tumor xenograft}

All animal work adhered to the Institutional Animal Care and Use Committee (IACUC) guidelines on animal use and handling. Female athymic BALB/c nude mice between 6 to 8 weeks old were maintained and handled in a pathogen-free environment under controlled conditions and received food and water ad libitum. Subconfluent H460 or H358 cells were resuspended in PBS at $40 \times 10^{6}$ cells $/ \mathrm{ml}$, and $0.1 \mathrm{ml}$ cell suspension was injected subcutaneously into the flanks of each animal. The tumors were measured with vernier calipers twice a week and the volume was calculated using the modified ellipsoidal formula (length $\times$ width $\left.^{2}\right) / 2$. Median tumor size at initiation of drug treatment was $50 \mathrm{~mm}^{3}$ (for $\mathrm{H} 460$ cells) and $200 \mathrm{~mm}^{3}$ (for H358 cells). Both PD and AZ were prepared in $1 \%$ polysorbate 80 (Sigma). The mice were randomized into four groups of five mice and gavage fed with vehicle control, or $12.5 \mathrm{mg} / \mathrm{kg} \mathrm{PD}$, or $50 \mathrm{mg} / \mathrm{kg}$ $\mathrm{AZ}$, or $12.5 \mathrm{mg} / \mathrm{kg} \mathrm{PD}$ and $50 \mathrm{mg} / \mathrm{kg} \mathrm{AZ} \mathrm{combination.} \mathrm{All}$ drugs were administered once a day, 5 days a week. The mice were euthanized and the xenograft tumors harvested after 3 weeks of drug treatment.

\section{Immunohistochemistry}

Xenograft tumors from control and compounds administered mice were fixed in formalin immediately after surgical excision, and subsequently paraffin embedded and sectioned. Tumor sections were deparaffinized using standard histologic procedures and stained with E-cadherin antibodies. Color development was performed using EnVision+ System-HRP (DAB) kit (Dako, Agilent Technologies) according the manufacturer's recommendation. Cell nuclei were counterstained with Hematoxylin (Thermo Scientific). Slide images were acquired with an optical imaging microscope at 20× magnification (Olympus IX71/DP71). Images were acquired from 3 tumor samples each for every treatment group.

Images were analyzed with ImageJ software using an image processing workflow described previously [43, 44]. Briefly, Hematoxylin and DAB stain color-separated images were derived from the original image using ImageJ Color Deconvolution plugin. Object segmentation using the Particle Analyzer plugin was then performed to identify the individual cellular regions in the image and the DAB intensity of each cell region in the image was then tabulated. E-cadherin staining was analyzed as the percentage of E-cadherin positive cells in each slide image. At least 20 images were analyzed for each tumor sample.

\section{Transfections}

For gene knockdown, CDH1 siRNA (sequence: 5'-GGCCUGAAGUGACUCGUAATT-3') and AllStar 
negative control siRNA were obtained from Qiagen. siRNA transfection was conducted with JetPRIME reagent (Polyplus Transfection). For gene overexpression, CDH1-GFP and p-CMV-entry empty vector plasmid constructs were obtained from OriGene Technologies. Plasmid transfection was conducted with ViaFect reagent (Promega).

\section{Statistical analysis}

All data were presented as mean \pm standard deviation (SD). The statistical significance of the data obtained was analyzed by two-way ANOVA for tumor xenograft results and Student's $t$-test for all other results. All statistical tests were 2-sided and the significance level was set at $P<0.05$.

\section{ACKNOWLEDGMENTS}

The authors would like to acknowledge the tissue slides preparation work performed by the Advanced Molecular Pathology Laboratory at IMCB, and the Centre for Translational Research and Diagnostics at CSI on STR analysis for cell line authentication. This work was funded by the Singapore Ministry of Health's National Medical Research Council (NMRC/ CSA/021/2010) to Boon Cher Goh, the National Research Foundation Singapore and the Singapore Ministry of Education under its Research Centres of Excellence initiatives.

\section{CONFLICTS OF INTEREST}

None.

\section{REFERENCES}

1. World Health Organization. GLOBOCAN 2012: Estimated cancer incidence, mortality and prevalence worldwide in 2012. 2015; March 4; Available from: http://globocan.iarc .fr/Pages/fact_sheets_population.aspx.

2. National Cancer Institute . SEER Stat Fact Sheets: Lung and Bronchus Cancer. 2015; March 4;. Available from: http://seer.cancer.gov/statfacts/html/lungb.html.

3. Siegel R, Naishadham D, Jemal A. Cancer statistics 2012. CA: a cancer journal for clinicians. 2012; 62:10-29.

4. Nurwidya F, Takahashi F, Murakami A, Takahashi K. Epithelial mesenchymal transition in drug resistance and metastasis of lung cancer. Cancer research and treatment: official journal of Korean Cancer Association. 2012; 44:151-156.

5. Bayraktar S, Rocha-Lima CM. Molecularly targeted therapies for advanced or metastatic non-small-cell lung carcinoma. World journal of clinical oncology. 2013; 4:29-42.
6. Ohashi K, Maruvka YE, Michor F, Pao W. Epidermal growth factor receptor tyrosine kinase inhibitor-resistant disease. Journal of clinical oncology: official journal of the American Society of Clinical Oncology. 2013; 31:1070-1080.

7. Lackner MR, Wilson TR, Settleman J. Mechanisms of acquired resistance to targeted cancer therapies. Future oncology. 2012; 8:999-1014.

8. Yun $\mathrm{CH}$, Mengwasser KE, Toms AV, Woo MS, Greulich H, Wong KK, Meyerson M, Eck MJ. The T790M mutation in EGFR kinase causes drug resistance by increasing the affinity for ATP. Proceedings of the National Academy of Sciences of the United States of America. 2008; 105:2070-2075.

9. Buck E, Eyzaguirre A, Rosenfeld-Franklin M, Thomson S, Mulvihill M, Barr S, Brown E, O’Connor M, Yao Y, Pachter J, Miglarese M, Epstein D, Iwata KK, Haley JD, Gibson NW, Ji QS. Feedback mechanisms promote cooperativity for small molecule inhibitors of epidermal and insulin-like growth factor receptors. Cancer research. 2008; 68:8322-8332.

10. Sos ML, Fischer S, Ullrich R, Peifer M, Heuckmann JM, Koker M, Heynck S, Stuckrath I, Weiss J, Fischer F, Michel K, Goel A, Regales L, Politi KA, Perera S, Getlik M, et al. Identifying genotype-dependent efficacy of single and combined PI3K- and MAPK-pathway inhibition in cancer. Proceedings of the National Academy of Sciences of the United States of America. 2009; 106:18351-18356.

11. Legrier ME, Yang CP, Yan HG, Lopez-Barcons L, Keller SM, Perez-Soler R, Horwitz SB, McDaid HM. Targeting protein translation in human non small cell lung cancer via combined MEK and mammalian target of rapamycin suppression. Cancer research. 2007; 67:11300-11308.

12. Acloque H, Adams MS, Fishwick K, Bronner-Fraser M, Nieto MA. Epithelial-mesenchymal transitions: the importance of changing cell state in development and disease. The Journal of clinical investigation. 2009; 119:1438-1449.

13. Thiery JP. Epithelial-mesenchymal transitions in tumour progression. Nature reviews Cancer. 2002; 2:442-454.

14. Chua KN, Sim WJ, Racine V, Lee SY, Goh BC, Thiery JP. A cell-based small molecule screening method for identifying inhibitors of epithelial-mesenchymal transition in carcinoma. PloS one. 2012; 7:e33183.

15. Thiery JP, Chua K, Sim WJ, Huang R. Epithelial mesenchymal transition during development in fibrosis and in the progression of carcinoma. Bulletin du cancer. 2010; 97:1285-1295.

16. D’Antonio C, Passaro A, Gori B, Del Signore E, Migliorino MR, Ricciardi S, Fulvi A, de Marinis F. Bone and brain metastasis in lung cancer: recent advances in therapeutic strategies. Therapeutic advances in medical oncology. 2014; 6:101-114.

17. Zimmermann S, Dziadziuszko R, Peters S. Indications and limitations of chemotherapy and targeted agents in 
non-small cell lung cancer brain metastases. Cancer treatment reviews. 2014; 40:716-722.

18. Berenbaum MC. Synergy, additivism and antagonism in immunosuppression. A critical review. Clinical and experimental immunology. 1977; 28:1-18.

19. Barrallo-Gimeno A, Nieto MA. The Snail genes as inducers of cell movement and survival: implications in development and cancer. Development. 2005; 132:3151-3161.

20. Webb DJ, Donais K, Whitmore LA, Thomas SM, Turner CE, Parsons JT, Horwitz AF. FAK-Src signalling through paxillin, ERK and MLCK regulates adhesion disassembly. Nature cell biology. 2004; 6:154-161.

21. Brown AP, Carlson TC, Loi CM, Graziano MJ. Pharmacodynamic and toxicokinetic evaluation of the novel MEK inhibitor, PD0325901, in the rat following oral and intravenous administration. Cancer chemotherapy and pharmacology. 2007; 59:671-679.

22. Green TP, Fennell M, Whittaker R, Curwen J, Jacobs V, Allen J, Logie A, Hargreaves J, Hickinson DM, Wilkinson RW, Elvin P, Boyer B, Carragher N, Ple PA, Bermingham A, Holdgate GA, et al. Preclinical anticancer activity of the potent, oral Src inhibitor AZD0530. Molecular oncology. 2009; 3:248-261.

23. Dehm SM, Bonham K. SRC gene expression in human cancer: the role of transcriptional activation. Biochemistry and cell biology = Biochimie et biologie cellulaire. 2004; 82:263-274.

24. Baselga J, Cervantes A, Martinelli E, Chirivella I, Hoekman K, Hurwitz HI, Jodrell DI, Hamberg P, Casado E, Elvin P, Swaisland A, Iacona R, Tabernero J. Phase I safety, pharmacokinetics, and inhibition of SRC activity study of saracatinib in patients with solid tumors. Clinical cancer research: an official journal of the American Association for Cancer Research. 2010; 16:4876-4883.

25. Laurie SA, Goss GD, Shepherd FA, Reaume MN, Nicholas G, Philip L, Wang L, Schwock J, Hirsh V, Oza A, Tsao MS, Wright JJ, Leighl NB. A phase II trial of saracatinib, an inhibitor of src kinases, in previously-treated advanced non-small-cell lung cancer: the princess margaret hospital phase II consortium. Clinical lung cancer. 2014; 15:52-57.

26. Gucalp A, Sparano JA, Caravelli J, Santamauro J, Patil S, Abbruzzi A, Pellegrino C, Bromberg J, Dang C, Theodoulou M, Massague J, Norton L, Hudis C, Traina TA. Phase II trial of saracatinib (AZD0530), an oral SRCinhibitor for the treatment of patients with hormone receptor-negative metastatic breast cancer. Clinical breast cancer. 2011; 11:306-311.

27. Mackay HJ, Au HJ, McWhirter E, Alcindor T, Jarvi A, MacAlpine K, Wang L, Wright JJ, Oza AM. A phase II trial of the Src kinase inhibitor saracatinib (AZD0530) in patients with metastatic or locally advanced gastric or gastro esophageal junction (GEJ) adenocarcinoma: a trial of the PMH phase II consortium. Investigational new drugs. 2012; 30:1158-1163.

28. Friday BB, Adjei AA. Advances in targeting the Ras/ Raf/MEK/Erk mitogen-activated protein kinase cascade with MEK inhibitors for cancer therapy. Clinical cancer research: an official journal of the American Association for Cancer Research. 2008; 14:342-346.

29. Henderson YC, Chen Y, Frederick MJ, Lai SY, Clayman GL. MEK inhibitor PD0325901 significantly reduces the growth of papillary thyroid carcinoma cells in vitro and in vivo. Molecular cancer therapeutics. 2010; 9:1968-1976.

30. LoRusso PM, Krishnamurthi SS, Rinehart JJ, Nabell LM, Malburg L, Chapman PB, DePrimo SE, Bentivegna S, Wilner KD, Tan W, Ricart AD. Phase I pharmacokinetic and pharmacodynamic study of the oral MAPK/ERK kinase inhibitor PD-0325901 in patients with advanced cancers. Clinical cancer research: an official journal of the American Association for Cancer Research. 2010; 16:1924-1937.

31. Haura EB, Ricart AD, Larson TG, Stella PJ, Bazhenova L, Miller VA, Cohen RB, Eisenberg PD, Selaru P, Wilner KD, Gadgeel SM. A phase II study of PD-0325901, an oral MEK inhibitor, in previously treated patients with advanced nonsmall cell lung cancer. Clinical cancer research: an official journal of the American Association for Cancer Research. 2010; 16:2450-2457.

32. Boasberg PD, Redfern CH, Daniels GA, Bodkin D, Garrett CR, Ricart AD. Pilot study of PD-0325901 in previously treated patients with advanced melanoma, breast cancer, and colon cancer. Cancer chemotherapy and pharmacology. 2011; 68:547-552.

33. Schliekelman MJ, Taguchi A, Zhu J, Dai X, Rodriguez J, Celiktas M, Zhang Q, Chin A, Wong CH, Wang H, McFerrin L, Selamat SA, Yang C, Kroh EM, Garg KS, Behrens C, et al. Molecular portraits of epithelial, mesenchymal and hybrid states in lung adenocarcinoma and their relevance to survival. Cancer research. 2015; 75:1789-1800.

34. Hanahan D, Weinberg RA. Hallmarks of cancer: the next generation. Cell. 2011; 144:646-674.

35. Said NA, Williams ED. Growth factors in induction of epithelial-mesenchymal transition and metastasis. Cells, tissues, organs. 2011; 193:85-97.

36. Chua KN, Poon KL, Lim J, Sim WJ, Huang RY, Thiery JP. Target cell movement in tumor and cardiovascular diseases based on the epithelial-mesenchymal transition concept. Advanced drug delivery reviews. 2011; 63:558-567.

37. Huang M, Shen A, Ding J, Geng M. Molecularly targeted cancer therapy: some lessons from the past decade. Trends in pharmacological sciences. 2014; 35:41-50.

38. Lin SH, George TJ, Ben-Josef E, Bradley J, Choe KS, Edelman MJ, Guha C, Krishnan S, Lawrence TS, Le QT, 
Lu B, Mehta M, Peereboom D, Sarkaria J, Seong J, Wang D, et al. Opportunities and challenges in the era of molecularly targeted agents and radiation therapy. Journal of the National Cancer Institute. 2013; 105:686-693.

39. Ferguson J, Arozarena I, Ehrhardt M, Wellbrock C. Combination of MEK and SRC inhibition suppresses melanoma cell growth and invasion. Oncogene. 2013; 32:86-96.

40. El Touny LH, Vieira A, Mendoza A, Khanna C, Hoenerhoff MJ, Green JE. Combined SFK/MEK inhibition prevents metastatic outgrowth of dormant tumor cells. The Journal of clinical investigation. 2014; 124:156-168.

41. Kowalski PJ, Rubin MA, Kleer CG. E-cadherin expression in primary carcinomas of the breast and its distant metastases. Breast cancer research: BCR. 2003; 5:R217-222.

42. Sundfeldt K, Piontkewitz Y, Ivarsson K, Nilsson O, Hellberg P, Brannstrom M, Janson PO, Enerback S,
Hedin L. E-cadherin expression in human epithelial ovarian cancer and normal ovary. Int J Cancer. 1997; 74:275-280.

43. Kong LR, Chua KN, Sim WJ, Ng HC, Bi C, Ho J, Nga ME, Pang YH, Ong WR, Soo RA, Huynh H, Chng WJ, Thiery JP, Goh BC. MEK inhibition overcomes Cisplatin resistance conferred by SOS/MAPK pathway activation in squamous cell carcinoma. Molecular cancer therapeutics. 2015; 14:1750-1760.

44. Tuominen VJ, Ruotoistenmaki S, Viitanen A, Jumppanen M, Isola J. ImmunoRatio: a publicly available web application for quantitative image analysis of estrogen receptor (ER), progesterone receptor (PR), and Ki-67. Breast cancer research: BCR. 2010; 12:R56. 